\title{
Sibunit Carbon-Based Cathodes for proton-Exchange-Membrane Fuel Cells
}

\author{
N.P. Lebedeva \\ A.S. Booij \\ I.N. Voropaev \\ P.A. Simonov
}

A.V. Romanenko 


\title{
Sibunit Carbon-Based Cathodes for Proton-Exchange-Membrane Fuel Cells ${ }^{\wedge}$
}

\author{
N. P. Lebedeva ${ }^{1 *}$, A. S. Booij ' , I. N. Voropaev² , P. A. Simonov² , and A. V. Romanenko \\ 1 Energy research Centre of the Netherlands (ECN), Westerduinweg 3, 1755 LE Petten, The Netherlands \\ 2 Boreskov Institute of Catalysis, Russian Academy of Sciences, Pr. Akademika Lavrentieva 5, 630090 Novosibirsk, Russia
}

Received December 02, 2008; accepted May 05, 2009

\section{Abstract}

Preparation, characterisation and evaluation of a novel cathode catalyst for $\mathrm{H}_{2} / \mathrm{O}_{2}$ PEMFC - 40 wt.- $\%$ Pt/Sibunit $1562 \mathrm{P}$ carbon - is presented. The performance of the cathodes based on the latter material is compared to that of a widely used commercially available reference material - $40 \mathrm{wt} . \mathrm{\%} \%$ Pt/Vulcan XC 72R - Hispec 4000 (Johnson Matthey, UK). It has been found that the mass activity of the $40 \mathrm{wt} .-\% \mathrm{Pt} /$ Sibunit 1562 P catalyst exceeds that of a commercial bench- mark by a factor of 2 due to a better dispersion of the $\mathrm{Pt}$ metal realised in the Sibunit - supported catalyst. Mass transport properties of the two catalysts studied are virtually equal.

Keywords: Proton-Exchange-Membrane Fuel Cells, $\mathrm{Pt} / \mathrm{C}$ Cathode Catalyst, Sibunit Carbon

\section{Introduction}

Carbon supported precious metal catalysts, mainly platinum and its alloys, are widely used in cathodes of the proton exchange membrane fuel cells (PEMFC) [1-3]. Since carbon forms the 'skeleton' of the catalytic layer of an electrode, its textural as well as physicochemical properties determine, to a large extent, the structure and transport properties of the layer and, therefore, influences its performance.

The most often utilised catalyst support materials for PEMFC are carbon blacks, whose properties and suitability for PEMFCs were examined in a number of publications ([1] and references therein, $[4,5])$. In search of better catalyst supports, various novel carbon materials, such as carbon nanotubes and nanofibers [6], ordered mesoporous carbons [7, 8] and disordered mesoporous carbons, such as Sibunit $[9,10]$, were recently evaluated in the fuel cells.

The latter class of materials - Sibunit - is a carbon black/ pyrolytic carbon synthetic composite produced by the pyrolysis of light hydrocarbons on the carbon black template followed by the steam activation of the resulting composite [11, 12]. As outlined in the ref. $[9,10]$ the unique characteristics of the Sibunit carbon, such as high electronic conductivity (ca.

- Paper presented at the 1st CARISMA conference Progress MEA 2008
$10 \mathrm{~S} \mathrm{~cm}^{-1}$ ), thermal and chemical stability, high mechanical stiffness (up to $300 \mathrm{~kg} \mathrm{~cm}^{-2}$ ), high purity (ash content below 0.3 wt.- $\%)$, make these materials especially attractive for the use as catalyst supports in PEMFCs. Moreover, the textural characteristics of the Sibunit carbon materials, such as surface area, pore size distribution and the agglomerate size and shape, can be varied in a wide range by choosing an appropriate template and synthesis conditions [11, 12].

A number of Sibunit materials with widely varying structural parameters were recently used for the preparation of the PtRu catalysts for anode in the direct methanol fuel cells [9] and $\mathrm{Pt} / \mathrm{C}$ catalysts for the cathode in $\mathrm{H}_{2} / \mathrm{O}_{2}$ PEMFC [10]. It has been found that PtRu catalysts supported on Sibunit materials, with low surface area of ca. $22-72 \mathrm{~m}^{2} \mathrm{~g}^{-1}$, showed metal utilisation close to $100 \%$ as well as increased mass and specific activity in methanol oxidation reaction compared to the catalysts supported on Sibunit materials with higher surface area [9]. The inferior activity of the latter catalysts was ascribed to a slow transference of the liquid reactants and/or gaseous reaction products in the pores with the diameter below $20 \mathrm{~nm}$ [9]. When Sibunit supported Pt catalysts are used in cathodes of $\mathrm{H}_{2} / \mathrm{O}_{2}$ fuel cell, an opposite trend has been observed [10]. Catalysts supported on the high surface area Sibunit materials exhibited much higher mass activity

[*] Corresponding author, lebedeva@ecn.nl 
compared to those supported on lower surface area Sibunit materials [10]. Kaiser et al. explained this effect by the improved mass transport and water management in the catalytic layers made of the former catalytic materials [10]. Specifically, mesopores with the diameter between 3 and $20 \mathrm{~nm}$ were concluded to serve as hydrophobic gas diffusion channels supplying oxygen to the surface of Pt particles supported on high-surface area Sibunit [10].

In this paper, a detailed study on the preparation, characterisation and evaluation of the $40 \mathrm{wt} . \mathrm{\%} \mathrm{Pt} /$ Sibunit $1562 \mathrm{P}$ catalyst in $\mathrm{H}_{2} / \mathrm{O}_{2}$ PEMFC is presented. We compare the performance of the cathodes based on the latter material to that of a widely used commercially available reference material 40 wt.-\% Pt/Vulcan XC 72R - Hispec 4000 (Johnson Matthey, $\mathrm{UK})$. We demonstrate that, contrary to what has been concluded in [10], the increased mass activity of the Pt catalyst supported on a high surface area Sibunit 1562P is related to a better dispersion of the Pt metal realised in this catalyst.

\section{Experimental}

\subsection{Catalyst Preparation and Characterisation}

40 wt.-\% Pt/Sibunit 1562P catalyst was prepared by deposition of platinum oxides onto carbon surface under redox-assisted hydrolysis of $\mathrm{Pt}(\mathrm{IV})$ chloride complexes in the presence of weak reducing agent as briefly described in the ref. [10]. Carbon powder $(0.2-4 \mu \mathrm{m})$ obtained by milling in planetary-type mill is suspended in aqueous $\mathrm{Na}_{2} \mathrm{PtCl}_{6}$ at room temperature and after heating at $80{ }^{\circ} \mathrm{C}$ a solution of $\mathrm{Na}_{2} \mathrm{CO}_{3}$ and $\mathrm{NaOOCH}$ is added drop-wise to the suspension under vigorous stirring, the value of $\mathrm{pH}$ being maintained between 6 and 7. After the addition, the slurry is aged and the catalyst is filtered, copiously washed with distilled water and dried in vacuum at $100{ }^{\circ} \mathrm{C}$ to be then reduced in a $\mathrm{H}_{2}$ stream at $150{ }^{\circ} \mathrm{C}$.

As prepared catalyst was characterised using high resolution transmission electron microscopy (HRTEM) and $X$-ray diffraction (XRD). HRTEM images were obtained on a JEM-2010 electron microscope (JEOL, Japan) at the accelerating voltage of $200 \mathrm{kV}$, metal particle size distribution was built from these images and used to calculate the average diameter of the $\mathrm{Pt}$ particles. The XRD pattern was recorded using X-ray diffractometer (Siemens, $\mathrm{CuK} a$ radiation) equipped with a high-temperature camera-reactor [13]. Metal dispersion degree (D) of the $40 \mathrm{wt} .-\%$ Pt/Sibunit 1562P catalyst was calculated using data on pulse $\mathrm{CO}$ chemisorption in $\mathrm{H}_{2}$ at $20^{\circ} \mathrm{C}$, assuming that each Pt surface atom adsorbs one $\mathrm{CO}$ molecule. Prior to the $\mathrm{CO}$ chemisorption measurement, the catalyst was reduced in the hydrogen flow at $120{ }^{\circ} \mathrm{C}$ for $30 \mathrm{~min}$.

Data on the metal dispersion degree and average $\mathrm{Pt}$ particle size of the 40 wt.-\% Pt/Vulcan XC 72R (Hispec 4000, Johnson Matthey) were obtained from the certificate of analysis supplied by the manufacturer. Following a suggestion of the reviewer, metal dispersion degree of the commercial bench- mark material Hispec 4000 was also measured by us using $\mathrm{CO}$ chemisorption. The measurements were performed on the same installation as for $40 \mathrm{wt} .-\% \mathrm{Pt} /$ Sibunit $1562 \mathrm{P}$ so that a direct comparison between the two catalysts would be justified. TEM images of the commercial benchmark material were obtained on a JEOL 1200E× II microscope at accelerating voltage of $120 \mathrm{kV}$.

Textural characteristics of the carbon support materials Sibunit 1562P and Vulcan XC 72 - were determined from the analysis of the nitrogen adsorption/desorption isotherms measured at $77 \mathrm{~K}$ using an automatic volumetric analyser ASAP 2400 (Micrometrics). Scanning electron microscopy (SEM) images of the Sibunit 1562P carbon were obtained using JSM 6460 LV (JEOL) electron microscope.

\subsection{Electrodes and MEA Preparation}

For the preparation of the catalytic ink for the cathodes, either Hispec 4000 (40 wt.-\% Pt on Vulcan XC 72R, Johnson Matthey, UK, Lot no. 128106003) or $40 \mathrm{wt} .-\% \mathrm{Pt} /$ Sibunit $1562 \mathrm{P}$ catalyst was mixed with an appropriate amount of 1,2propanediol, 10 wt.-\% Fumion [PFSA, EW = 900; FuMA Tech $\mathrm{GmbH}$, Germany (Specifications of the FuMION and FuMAPEM materials can be found under:http://www. fumatech.de)] in 1,2-propanediol and a small amount of stabiliser by ultrasonication. The ink was applied on the H2315 C2 GDL (Freudenberg FCCT KG, Germany) by screen-printing. Thereafter, the electrodes produced were dried under an inert atmosphere and a thin layer of the ionomer was applied on the surface of the catalytic layer. A number of the ink compositions were prepared so that the ionomer content in the cathode catalytic layer varied between 26 and $36 \mathrm{wt} .-\%$. The Pt loading of the cathodes was ca. $0.26-0.30 \mathrm{mg} \mathrm{Pt} \mathrm{cm}^{-2}$.

Anodes were prepared in the same way, except that Hispec 9100 (60 wt.-\% Pt/AC01, Johnson Matthey, UK) was used as a catalyst and the ionomer content in the catalytic layer was kept at 20 wt.-\%. The Pt loading was kept at ca. 0.35-

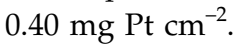

MEAs were prepared by sandwiching a piece of a FuMAPEM membrane [PFSA, EW $=900$, ca. $50 \mu$ m-thick; FuMA Tech GmbH, Germany (Specifications of the FuMION and FuMAPEM materials can be found under: http:// www.fumatech.de) between two electrodes by hot-pressing at $135{ }^{\circ} \mathrm{C}$.

\subsection{MEA Characterisation and Testing}

The MEAs were operated at $65^{\circ} \mathrm{C}$ and full humidification of the feed gases; start-up was performed at a constant current density of $0.5 \mathrm{~A} \mathrm{~cm}^{-2}$. Polarisation measurements in air and in oxygen were performed at atmospheric pressure, 1.5 and 2/10 stoichiometry for hydrogen and air/oxygen, respectively. Much higher stoichiometries were applied at the current densities below $0.3 \mathrm{~A} \mathrm{~cm}^{-2}$ in order to ensure low utilisation in the kinetic region. Each point of the polarisation curve was measured galvanostatically by averaging the cell voltage 
over the last $30 \mathrm{~s}$ after waiting for $4.5 \mathrm{~min}$ at a given setpoint (5 min in total).

MEA characterisation was performed at regular intervals of time and included hydrogen cross-over measurement, $\mathrm{Pt}$ electrochemically active surface area (ECSA) measurement at the cathode using cyclic voltammetry $(\mathrm{CV})$, measurement of the total Ohmic cell resistance as well as proton resistance of the cathode catalytic layer using electrochemical impedance spectroscopy (EIS).

Hydrogen cross-over was measured on a cell supplied with hydrogen at the anode and nitrogen at the cathode at 1.5 bar (absolute) gas pressure at a potential minimum of the $\mathrm{Pt}$ double layer region of the cathode (typically $0.40-0.45 \mathrm{~V}$ cell voltage, depending on the catalyst). The values for hydrogen cross-over for FuMaPEM 950 membrane were found to be in the order of $1 \mathrm{~mA} \mathrm{~cm}^{-2} \mathrm{bar}^{-1}$, in agreement with the literature data for a standard Nafion 112 of comparable thickness.

Voltammetric measurements were also performed on the cell supplied with hydrogen at the anode and nitrogen at the cathode at atmospheric gas pressure and a scan rate of $50 \mathrm{mV} \mathrm{s}^{-1}$ in the potential region between 80 and $700-750 \mathrm{mV}$ versus RHE ECSA of Pt of the cathode was determined by integrating the charge for the oxidation of the Hupd on $\mathrm{Pt}$ assuming the formation of a monolayer of adsorbed $\mathrm{H}$ and 1:1 adsorption stoichiometry. Particular care was taken to avoid significant evolution of molecular hydrogen during the $\mathrm{CV}$ measurements as its re-oxidation would lead to a large overestimation of the Hupd charge and, hence, to an overestimation of the Pt ECSA and Pt utilisation.

EIS measurements were performed galvanostatically at various constant current densities, typically 50, 100 and $400 \mathrm{~mA} \mathrm{~cm}^{-2}$, on a cell supplied with hydrogen at the anode and oxygen at the cathode at atmospheric gas pressure. Investigated frequency range was between 1 and $10^{5} \mathrm{~Hz}$. The total Ohmic cell resistance was determined at the point of the intersection of the impedance spectrum with the X-axis on the Nyquist plot, typically at frequencies of $1 \times 10^{4}-$ $5 \times 10^{4} \mathrm{~Hz}$. The proton resistance in the catalytic layer of the cathode was determined from the high frequency region of the impedance spectra exhibiting $45^{\circ}$ angle, typically between 1 and $4 \mathrm{kHz}$, according to the approach outlined in [14, 15].

For the analysis of the kinetic region of a polarisation curve in order to determine the specific and mass activity of the catalysts, polarisation data points recorded in $\mathrm{H}_{2} / \mathrm{O}_{2}$ were corrected for the hydrogen cross-over and Ohmic resistance of the cell. Both specific and mass activity of the catalysts were determined at $0.9 \mathrm{~V}$ (IR-free) and corrected to a standard state of $\mathrm{p}_{\mathrm{O}_{2}}=\mathrm{p}_{\mathrm{H}_{2}}=1 \mathrm{~atm}$ as described in the ref. [16]. The mass and specific activity numbers reported are averaged values of two parallel measurements performed on two MEAs, prepared in the same way.

\section{Results and Discussion}

\subsection{Catalyst Characterisation}

Textural characteristics, such as BET surface area and total pore volume of the Sibunit 1562P and Vulcan XC 72 materials, are compared in Table 1. It can be seen that Sibunit 1562P carbon has almost twice as high BET surface area compared to Vulcan XC 72 and ca. 30\% bigger total pore volume. Pore size distributions of these materials (shown in Figure 1) differ mainly in the region of small mesopores, i.e. pores with a diameter below ca. $10 \mathrm{~nm}$. Sibunit 1562P has a large portion of its surface area and its total pore volume located in the small mesopores, while this type of pores is virtually absent in Vulcan XC 72 material. Both carbon supports have noticeable amount of large mesopores with a diameter between ca. 10 and $30 \mathrm{~nm}$. Compared to Vulcan XC 72, Sibunit 1562P has almost twice as low amount of the macropores.

Figure 2a shows a TEM image of the Sibunit 1562P carbon support. Morphology, characteristic of the Sibunit class of materials, i.e. spherical hollow primary particles and their fragments, interconnected to each other to form aggregates, is clearly visible. For the particular case of Sibunit 1562P, the primary spherical particles are about $100 \mathrm{~nm}$ in diameter and their aggregates are presented as hard carbon grains yielded by mortaring of the Sibunit granules. These grains are of irregular shape and are $0.1-4 \mu \mathrm{m}$ in size (Figure $2 \mathrm{~b}$ ), their void space mainly replicating the carbon body of carbon black used as a template for the production of Sibunit.

TEM image of the $40 \mathrm{wt} .-\% \mathrm{Pt} /$ Sibunit $1562 \mathrm{P}$ catalyst is shown in Figure 3. It is seen that Pt nanoparticles are densely distributed over the surface of Sibunit carbon support and that the particle size distribution is narrow and is centered at $2.86 \mathrm{~nm}$. The XRD pattern of the $40 \mathrm{wt} .-\% \mathrm{Pt} /$ Sibunit 1562P catalyst is shown in Figure 4. Analysis of the diffraction data showed that platinum crystallites possess isometric shape and are ca. $3.3 \mathrm{~nm}$ in size. From the $\mathrm{CO}$ chemisorption measurements platinum dispersion as high as 0.32 , which corresponds to the average-surface diameter of ca. $3.37 \mathrm{~nm}$ for the Pt particles, was calculated. Good agreement between the results of the catalyst dispersion characterisation indicates

Table 1 Characteristics of the support- and catalyst materials.

\begin{tabular}{|c|c|c|c|}
\hline Carbon support & & Sibunit 1562P & Vulcan XC 72 \\
\hline $\begin{array}{l}\text { BET surface area } \\
\left(\mathrm{m}^{2} \mathrm{~g}^{-1}\right)\end{array}$ & & 450 & 252 \\
\hline $\begin{array}{l}\text { Total pore volume } \\
\left(\mathrm{cm}^{3} \mathrm{~g}^{-1}\right)\end{array}$ & & 0.86 & 0.63 \\
\hline $\begin{array}{l}\text { Micropore volume } \\
\left(\mathrm{cm}^{3} \mathrm{~g}^{-1}\right)\end{array}$ & & $-0.035^{\mathrm{a})}$ & 0.037 \\
\hline Catalyst & & $\begin{array}{l}40 \text { wt.- } \% \text { Pt/Sibunit } \\
1562 \mathrm{P}\end{array}$ & $\begin{array}{l}40 \text { wt.-\% Pt/Vulcan } \\
\text { XC 72R(lot no. } \\
128106003 \text { ) }\end{array}$ \\
\hline Pt particle size $(\mathrm{nm})$ & XRD & 3.3 & $3.2^{\mathrm{b})}$ \\
\hline $\begin{array}{l}\text { Pt surface area } \\
\left(\mathrm{m}^{2} \mathrm{~g}_{\mathrm{Pt}}^{-1}\right)\end{array}$ & CO chemisorption & 83 & $49.466^{8)}$ \\
\hline
\end{tabular}

a) Micropores volume is determined as an intercept of the $t$-plot, its negative value indicates that the micropores are absent.

b) Data from the certificate of analysis, supplied by the manufacturer. 


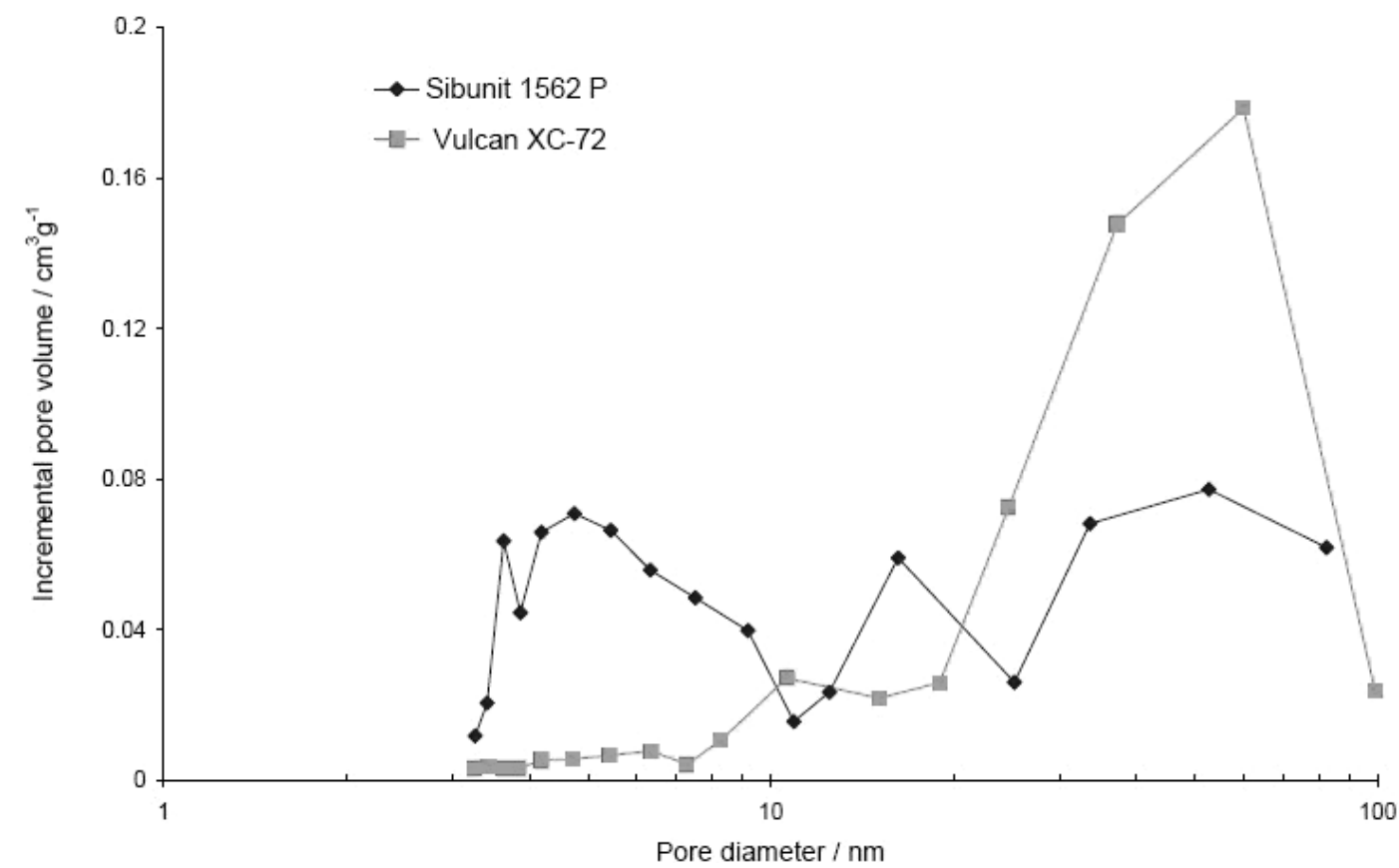

Fig. 1 Pore size distributions of Sibunit 1562P and Vulcan XC 72 materials as derived from the desorption branch of the $\mathrm{N}_{2}$ adsorption isotherms by BJH method.
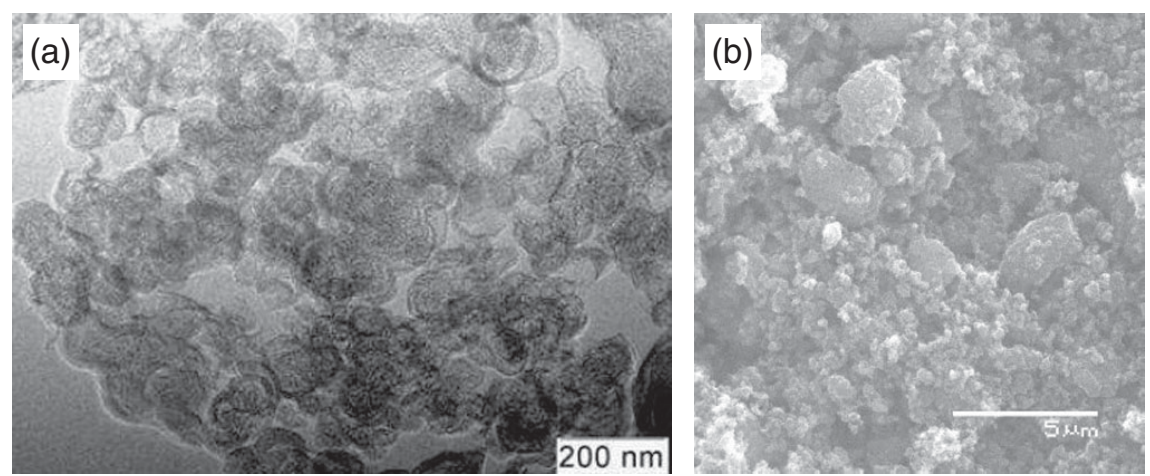

Fig. 2 (a) TEM image of Sibunit 1562P support, (b) SEM image of Sibunit 1562P support.

\subsection{MEA Testing}

Figure 6a shows the polarisation curves of the MEAs manufactured with 40 wt.- $\%$ Pt/Sibunit $1562 \mathrm{P}$ as cathode catalyst and the ionomer content in the cathode catalytic layer varying from 26 and 36 wt.- $\%$. Figure $6 \mathrm{~b}$ presents the corresponding curves for Hispec 4000. For both sets of MEAs, the well-known effects of gradually improving performance with increasing ionomer content are visible when the ionomer content in the cathode catalytic layer increases from 26 to $33 \mathrm{wt} . \%$. With further increase in

that the active component in the prepared catalyst is in the form of nonagglomerated, monocrystalline platinum particles.

Commercial reference material 40 wt.- $\%$ Pt/Vulcan XC 72R (Hispec 4000, lot no. 128106003) had Pt crystallites of ca. $3.2 \mathrm{~nm}$ in size as determined by the manufacturer on the basis of the XRD data. The metal surface area of $66 \mathrm{~m}^{2} \mathrm{~g}_{\mathrm{Pt}}{ }^{-1}$ was specified in the certificate of analysis supplied by a manufacturer. Our own measurements, performed on the same installation as for the $40 \mathrm{wt} .-\% \mathrm{Pt} /$ Sibunit $1562 \mathrm{P}$ catalyst, yielded, however, a somewhat lower value of $49.4 \mathrm{~m}^{2} \mathrm{~g}_{\mathrm{Pt}}{ }^{-1}$. The difference between the two values might originate from a different adsorption stoichiometry of $\mathrm{CO}$ on $\mathrm{Pt}$, assumed in the calculation of the metal surface area. Figure 5 shows TEM images of the Hispec 4000 material. Carbon support of Hispec 4000 possesses morphological features close to commercial Vulcan XC 72. the ionomer content up to $36 \mathrm{wt} . \mathrm{\%}$, the performance of the MEAs drops.

A similar volcano-type dependence of the cell performance on the ionomer content in the catalytic layer was previously reported [17-19] and was attributed to the fact that at the ionomer content lower than the optimum the cathodes exhibit low catalyst utilisation and high proton resistance. When the ionomer is present in excess mass transport phenomena become more pronounced, in particular, oxygen diffusion to the reaction sites becomes hindered and the catalyst utilisation decreases.

Polarisation curves for the two sets of MEAs are very similar (see Figures 6a and b), except that the Sibunit-based MEAs perform better at the current densities below ca. $0.25 \mathrm{~A} \mathrm{~cm}^{-2}$, i.e. in the potential region where the performance of the cell is determined mainly by the kinetics of the oxygen reduction reaction $(\mathrm{ORR})$ at the cathode. Taking into account that the $\mathrm{Pt}$ 

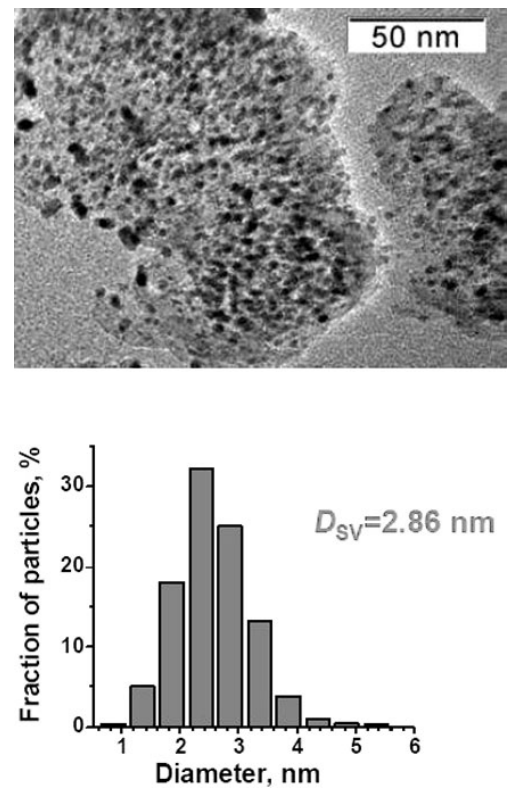

Fig. 3 TEM image of 40 wt.-\% Pt/Sibunit 1562P catalyst and Pt particle size distribution for this material.

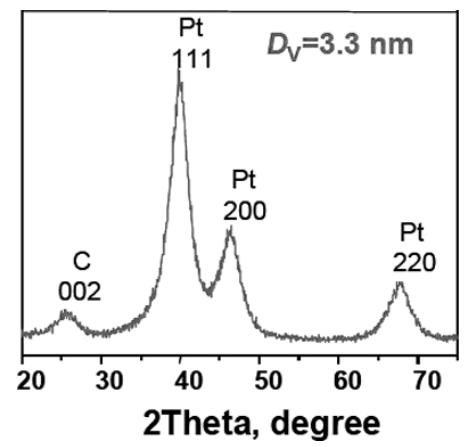

Fig. 4 XRD pattern of 40 wt. $\%$ Pt/Sibunit 1562P catalyst.

loading of the Hispec 4000 cathodes is ca. 15\% higher than that of the cathodes based on $40 \mathrm{wt} . \mathrm{\%} \mathrm{Pt} / \mathrm{Sibunit} 1562 \mathrm{P}$, one can conclude that the mass activity of the latter catalyst is noticeably higher than that of the commercial benchmark Hispec 4000 material. At higher current densities, polarisation curves for the two sets of MEAs go almost parallel, indicating that the IR- and mass transport losses are similar for the two types of MEAs, maintaining a small difference of ca. $10 \mathrm{mV}$ that originates from the higher kinetic activity of the 40 wt.-\% Pt/Sibunit 1562P catalyst. More detailed discussion of the kinetic and transport characteristics of these two catalytic materials is presented below.

\subsubsection{Kinetic Activity and Catalyst Utilisation}

Figure 7a presents a comparison of the mass activity of the two catalysts in the potential region between ca. 0.95 and $0.8 \mathrm{~V}$. It can be seen that the mass activity of the $40 \mathrm{wt} .-\% \mathrm{Pt} /$ Sibunit $1562 \mathrm{P}$ catalyst at $0.9 \mathrm{~V}$ is ca. $70 \mathrm{Ag}_{\mathrm{Pt}}{ }^{-1}$, which is almost twice as high compared that of Hispec 4000 lot no. 128106003,
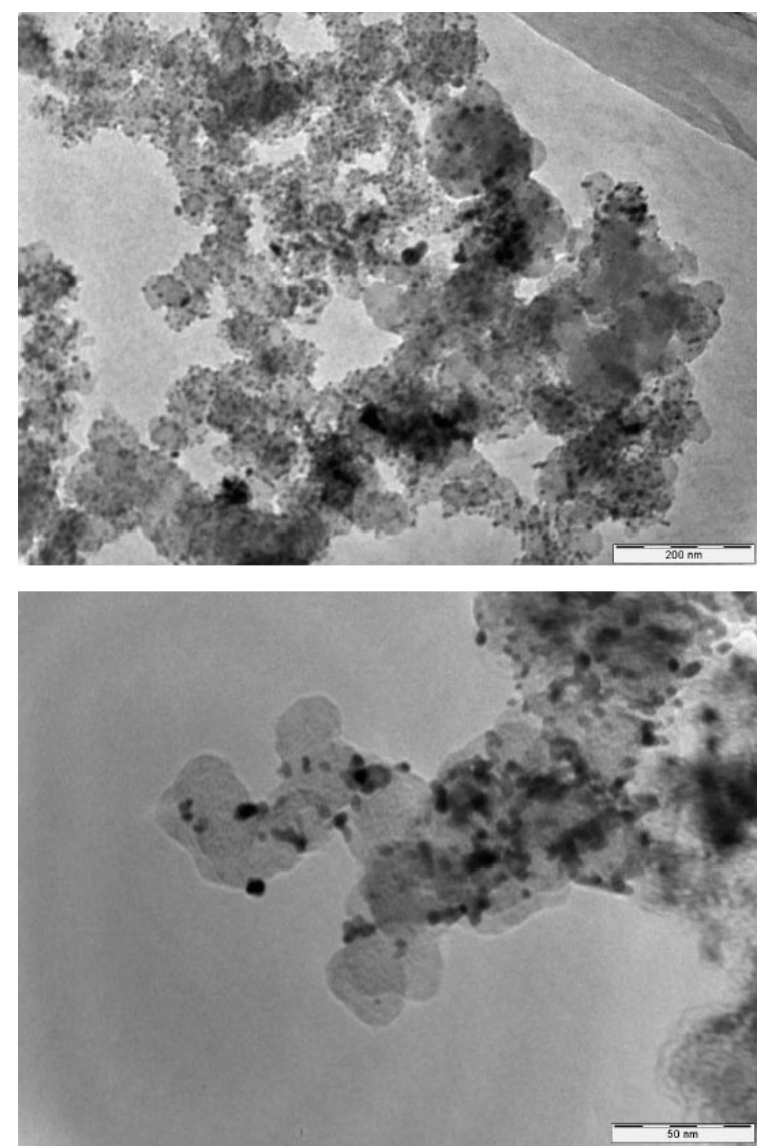

Fig. 5 TEM images of the Hispec 4000 catalyst lot no. 128106003.

ca. $40 \mathrm{Ag}_{\mathrm{Pt}}{ }^{-1}$, this trend is maintained in the whole potential range. Figure $7 \mathrm{~b}$ demonstrates that $40 \mathrm{wt} .-\% \mathrm{Pt} /$ Sibunit 1562P material shows higher ORR mass activity compared to the Hispec 4000 catalyst at any ionomer content of the cathode catalytic layer. Dependence of the mass activity in ORR on the ionomer content in the catalytic layer exhibits a maximum, which in this case lies at ca. $30 \mathrm{wt} .-\%$ of the ionomer (ionomer/carbon ratio of 0.75 ) in the cathode catalytic layer.

Mass activity at a given potential is defined as follows:

$i_{\mathrm{m}}=i_{\mathrm{s}} \mathrm{ECSA}=i_{\mathrm{s}} S_{\mathrm{Pt}} u$

where $i_{\mathrm{s}}$ is specific activity of a catalyst and ECSA - electrochemically active $\mathrm{Pt}$ surface area of the $\mathrm{Pt} / \mathrm{C}$ catalyst, which, in turn, is defined as a product of $S_{\mathrm{Pt}}-\mathrm{Pt}$ surface area measured in the gas phase by, for example, CO chemisorption, and $u$-utilisation of the catalyst. All three parameters $-i_{\mathrm{s}}, S_{\mathrm{Pt}}$ and $u-$ will therefore influence the mass activity of a catalyst.

Figure 7c shows that the specific activities of the two catalysts are very similar (within the error of the measurement [20]), ca. $110 \pm 10 \mu \mathrm{A} \mathrm{cm} \mathrm{cm}^{-2}$, as it could be expected for two materials with similar composition - pure Pt- and similar Pt particle size - ca. $3.3 \mathrm{~nm}$ for $40 \mathrm{wt}$. $\% \mathrm{Pt} /$ Sibunit $1562 \mathrm{P}$ and $3.2 \mathrm{~nm}$ for Hispec 4000 lot no. 128106003. If normalised to the cell temperature of $80^{\circ} \mathrm{C}$, our results agree well with the pre- 


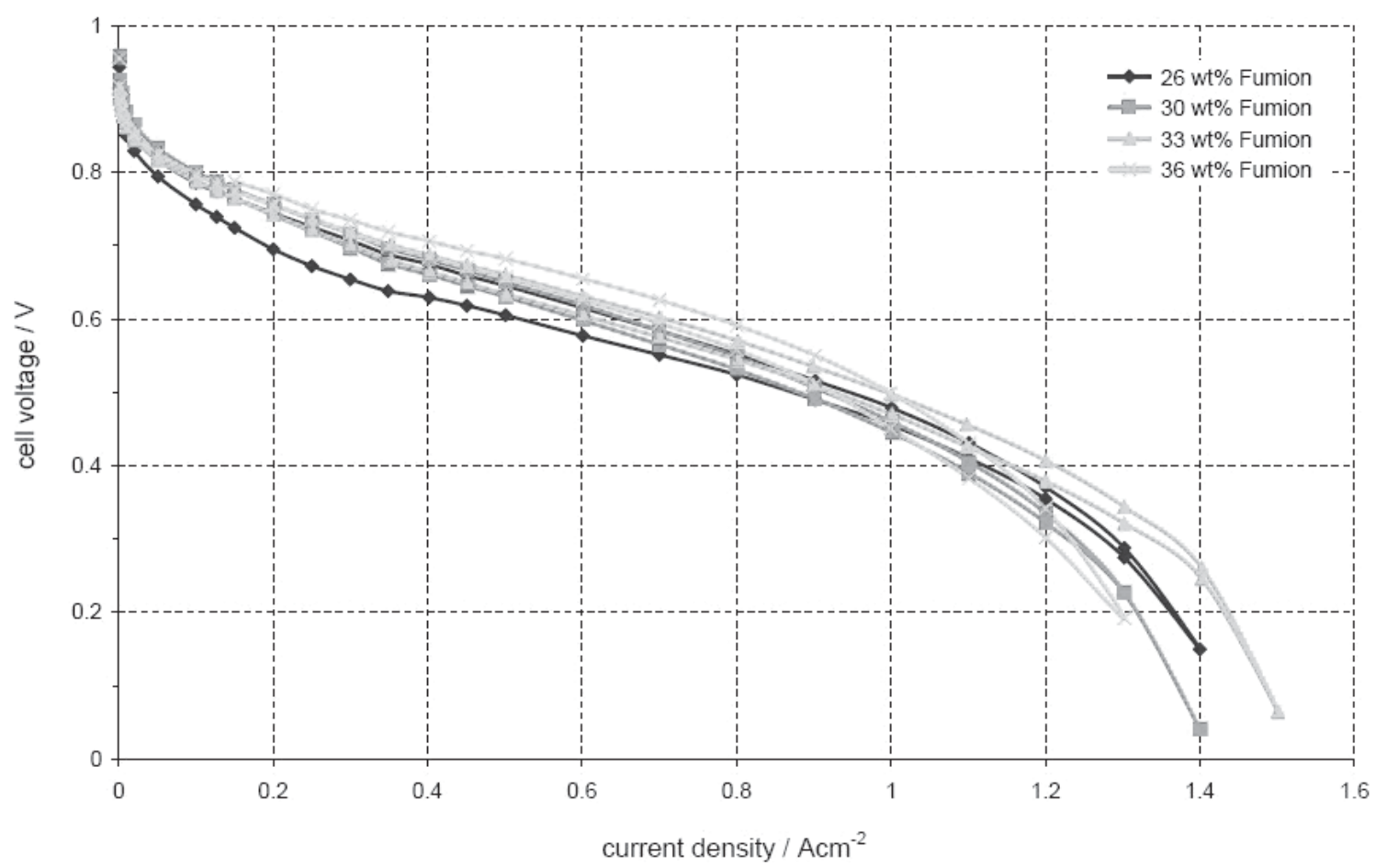

(a)

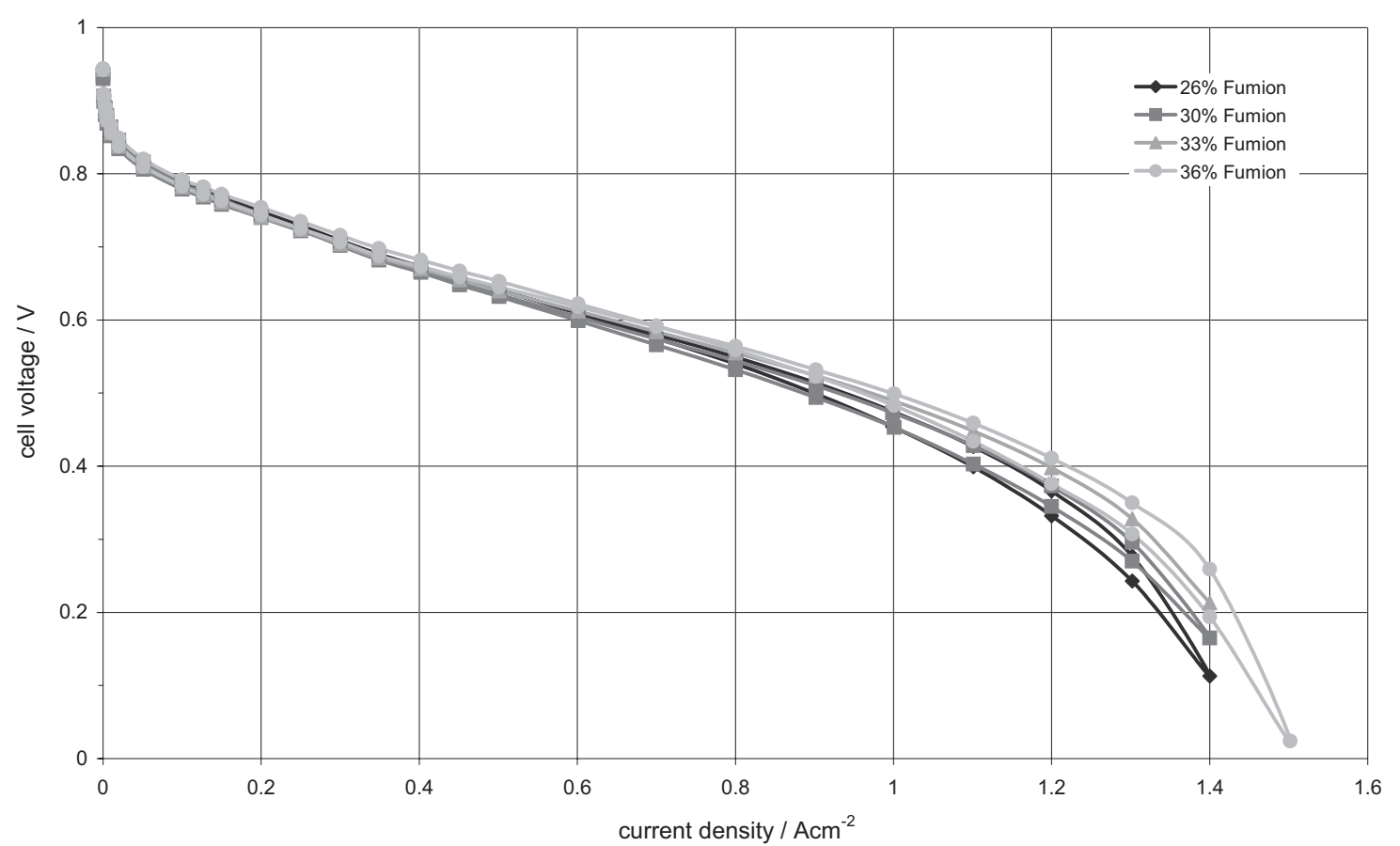

(b)

Fig. 6 Polarisation curves of the MEAs with (a) 40 wt.- $\%$ Pt/Sibunit 1562P and (b) 40 wt.- $\%$ Pt/Vulcan XC 72 R (Hispec 4000, lot no. 128106003) cathodes. H2315 C2 GDL, FuMaPEM 950 membrane, $65^{\circ} \mathrm{C}$, full humidification, 1 bar absolute gas pressure, stoichiometry hydrogen/air = 1.5:2.0, Pt loading at the cathode ca. $0.26-0.30 \mathrm{mg} \mathrm{cm}^{-2}$.

viously published data [16]. Since the specific activity of the studied catalysts is almost the same, higher mass activity of the 40 wt.- $\%$ Pt/Sibunit $1562 \mathrm{P}$ catalyst must be a consequence of a higher ECSA available in this material.
Surface area of Pt in 40 wt.- $\%$ Pt/ Sibunit 1562P catalyst is ca. 1.7 times higher compared to that of Hispec 4000 lot no. 128106003 (see Table 1). As shown in Figure 8, the utilisation of $\mathrm{Pt}$ in the $40 \mathrm{wt} .-\% \mathrm{Pt} /$ Sibunit 1562P catalyst is as high as 


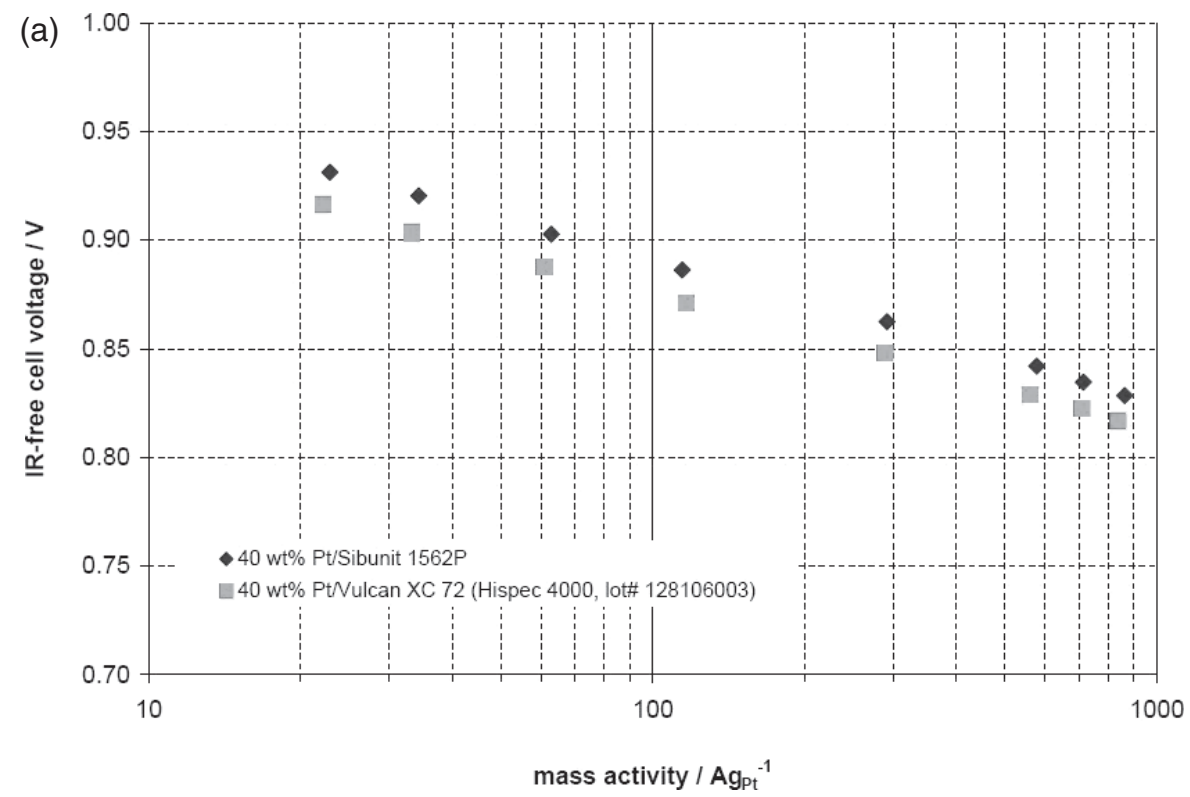

(b)
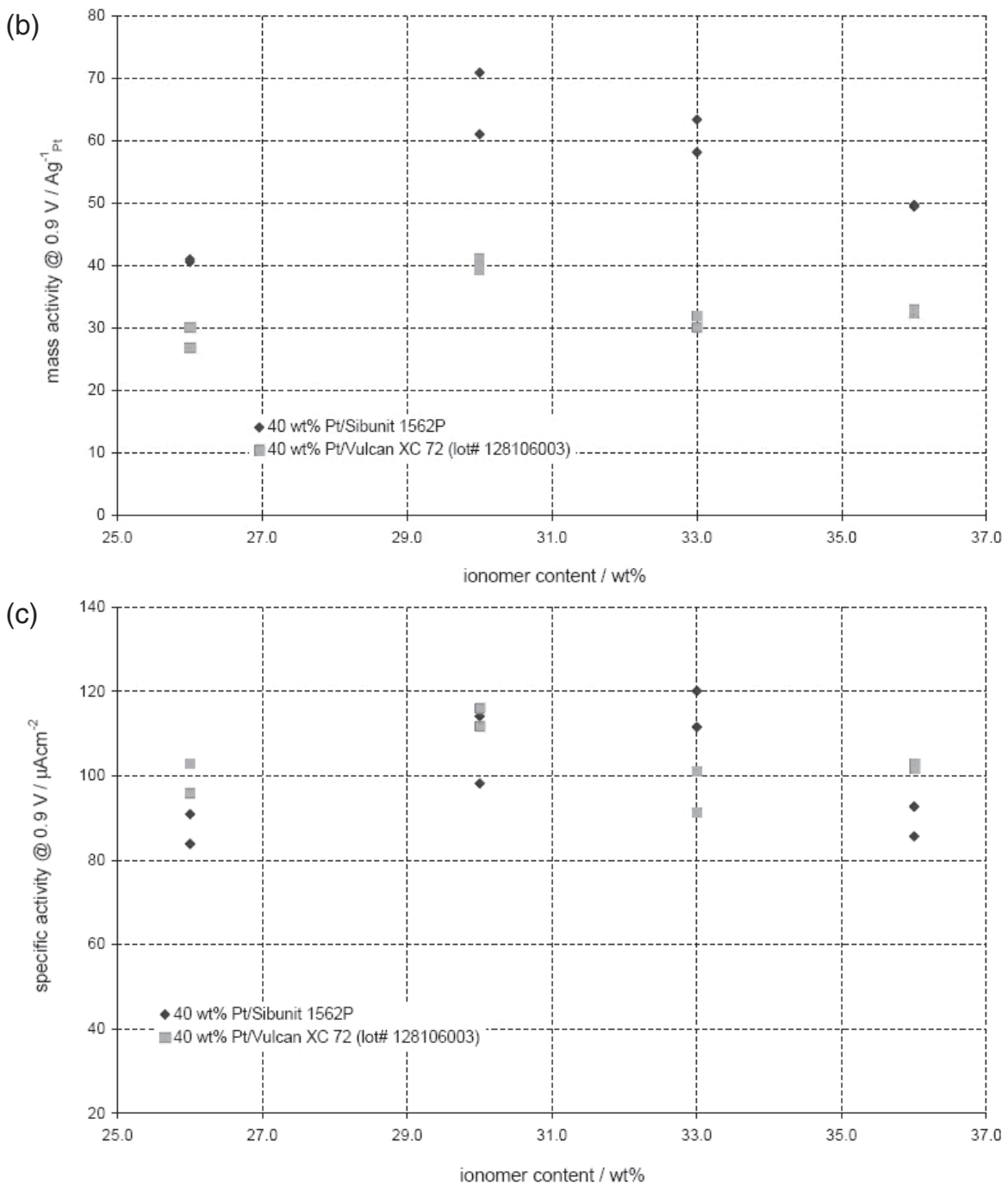

Fig. 7 (a) Comparison of the mass activity of the 40 wt.- $\%$ Pt/Sibunit 1562P and 40 wt.- $\%$ Pt/Vulcan XC 72 (Hispec 4000, lot no. 128106003) catalysts in the potential range between 0.95 and $0.8 \mathrm{~V}$; ionomer content in the cathode catalytic layer is $33 \mathrm{wt} . \%$ for both catalysts; measurements in $\mathrm{H}_{2} / \mathrm{O}_{2}$, (b) dependence of the mass activity of the catalysts determined at $0.9 \mathrm{~V}$ on the ionomer content in the cathode catalytic layer; measurements in $\mathrm{H}_{2} / \mathrm{O}_{2}$, (c) comparison of the specific activity of the catalysts at $0.9 \mathrm{~V}$, measurements in $\mathrm{H}_{2} / \mathrm{O}_{2}$. 


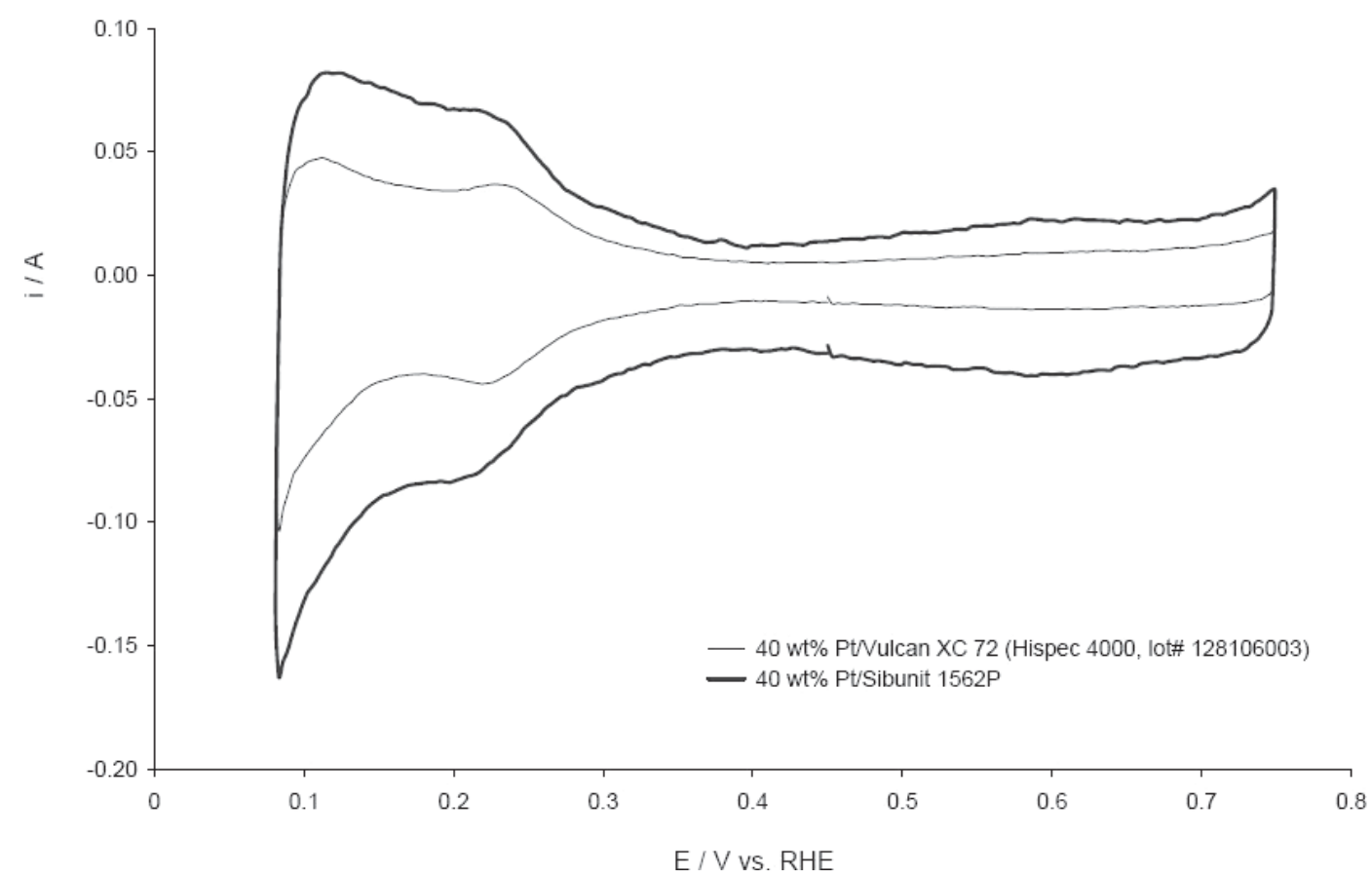

(a)

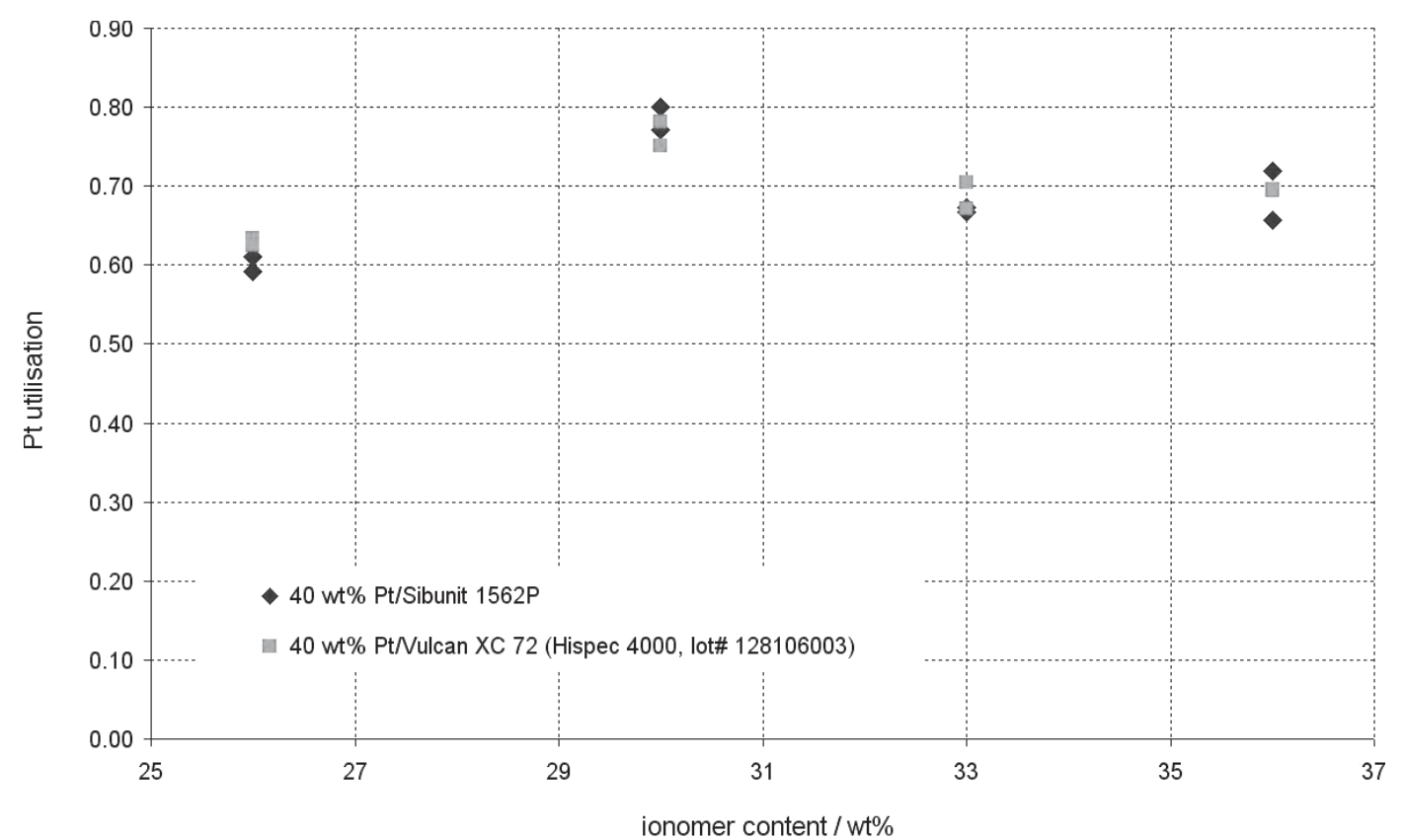

(b)

Fig. 8 (a) Cyclic voltammogram of the cathodes based on 40 wt.- $\%$ Pt/Sibunit 1562P and 40 wt.-\% Pt/Vulcan XC 72 (Hispec 4000 , lot no. 128106003) catalysts, both electrodes had 30 wt. $\%$ ionomer in the catalytic layer, (b) utilisation of $\mathrm{Pt}$ as a function of the ionomer content of the cathode catalytic layer.

that in Hispec 4000, varying between 60 and $80 \%$ in the studied range of ionomer content. For both catalysts, a maximum of Pt utilisation at ca. $30 \mathrm{wt}$. $\%$ of ionomer is observed. Utilisation of the catalyst is low at low amounts of the ionomer in the catalytic layer due to the lack of the contact between the oxygen reduction sites and the ionomer. Utilisation gradually improves as the ionomer content increases; at too high iono- mer content, however, some of the catalyst particles become encapsulated in the ionomer and lose electric contact with the rest of the electrode, thus becoming unutilised (see, e.g. [21]).

Since the utilisation of $\mathrm{Pt}$ is equally high for both catalysts studied, a higher ECSA of Pt for the $40 \mathrm{wt}$. $\%$ Pt/Sibunit $1562 \mathrm{P}$ is primarily related to a better dispersion of $\mathrm{Pt}$ realised in this catalyst. 
It has been long believed that only $\mathrm{Pt}$ particles in direct contact with or covered by the ionomer can be utilised in ORR. It might therefore seem a bit surprising that there is no influence of the porous structure of the catalyst support on the utilisation of Pt for the two catalysts studied here (Figure 8). As it can be seen in Figure 1, compared to Vulcan XC 72 , Sibunit $1562 \mathrm{P}$ has a noticeably bigger amount of mesopores with a diameter smaller than ca. $10 \mathrm{~nm}$ and a lower amount of the pores with the diameter bigger than ca. $40 \mathrm{~nm}$. The small pores are unlikely to be accessible for the ionomer, whose particles were found to be ca. $40 \mathrm{~nm}$ in diameter for the dispersion of Flemion ${ }^{\circledR}(\mathrm{EW}=900)$ in butyl acetate [4], ca. $6 \mathrm{~nm}$ in diameter and ca. $100 \mathrm{~nm}$ in length for a dilute dispersion of Nafion $^{\circledR}(E W=1,100)$ in water [22] and ca. $5-8 \mathrm{~nm}$ for an individual ionomer particle in a dispersion of Fumion ${ }^{\circledR}$ [23]. It should be noted, however, that there is a strong tendency for agglomeration, which is especially relevant when ionomer particle distribution in a real ink is considered [23]. Obviously, the particle size of the ionomer in the dispersion depends strongly on the equivalent weight of the ionomer, its concentration in the dispersion, type of solvent, etc. Nevertheless, it seems that the ionomer forms particles which are almost always too big to penetrate the pores smaller than ca. $10 \mathrm{~nm}$ in diameter. One can argue that the ionomer changes its configuration when incorporated into an electrode and spreads out to cover the carbon and Pt surfaces. It is not very likely to occur in our system as interactions between the catalyst and the ionomer are mainly of van der Waals type, i.e. relatively weak [24]. Thermal treatment of a catalytic ink was shown to result in a nearly even distribution of the ionomer through the catalytic layer, thereby improving the utilisation of the Pt metal [25], but much higher temperatures than those used in the present study are required in order to achieve this effect. Also, compared to Vulcan XC 72, Sibunit 1562P has a lower amount of the pores with the diameter bigger than ca. $40 \mathrm{~nm}$, which are undoubtedly accessible for the ionomer, and hence proportionally lower amount of Pt located in these pores. Both effects - inaccessibility of the small mesopores for the ionomer and smaller amount of $\mathrm{Pt}$ located in the larger meso- and macropores of Sibunit $1562 \mathrm{P}$ - should in principle lead to a lower utilisation of Pt in 40 wt.-\% Pt/Sibunit 1562P catalyst compared to that in Hispec 4000. As Figure 8 shows this trend is not observed experimentally.

It is likely that the formation of an adsorbed film of liquid water on the pore walls or even condensation of the product water in the small mesopores increases the utilisation of $\mathrm{Pt}$ in 40 wt.- $\%$ Pt/Sibunit 1562P catalyst. In this case, water, which is in contact with the ionomer, serves as a proton conductor, whose proton conductivity is good enough to conduct protons on a short distance. This 'Grotthus-like' path of proton conduction is used in the ultra-thin ionomer-free nanostructured electrodes developed by $3 \mathrm{M}$ [26], recent theoretical simulations confirmed that efficient proton transport through water-filled pores in the catalyst can occur and increase the catalyst utilisation [27]. Several experimental studies conducted on Pt black and carbon supported Pt catalysts showed that Pt sites, which are not in direct contact with the ionomer, can be electrochemically active and contribute to the Pt utilisation (see, e.g. [8, 28, 29 and references therein]). We discuss various aspects of the catalyst utilisation in PEMFC and how the factors, such as porous structure of the catalyst, its hydrophobicity, electrode thickness, etc., may influence the utilisation of a catalyst elsewhere.

It is also interesting to note that, compared to Hispec 4000, there is a noticeably higher amount of the oxygen-containing groups on the carbon surface of $40 \mathrm{wt}$ - $\% \mathrm{Pt} /$ Sibunit $1562 \mathrm{P}$ catalyst as evidenced by the presence of a broad peak at ca. $0.58 \mathrm{~V}$ versus RHE on its CV (see Figure 8a). This, however, does not make this material more prone to flooding or degradation (see the discussion below).

\subsubsection{Transport Properties}

Transport properties of the cathode are of crucial importance for the functioning of a fuel cell. These include transport of protons through the ionomer web in the catalytic layer, oxygen diffusion through the gas diffusion layer (GDL) as well as through the catalytic layer, water removal from the reaction site through the catalytic layer and further through the GDL. If the structure of the carbon support of a catalyst is altered, this might cause a change in all of the mass transport characteristics of the catalytic layer. Below, we compare the transport properties of the electrodes made using $40 \mathrm{wt} .-\%$ Pt/Sibunit 1562P and 40 wt.-\% Pt/Vulcan XC 72R (Hispec 4000) catalysts and try to correlate those with the porous structure of the catalysts.

Figure 9a shows the dependence of the proton resistance $\left(R_{\mathrm{p}}\right)$ of the cathode catalytic layer on its ionomer content. As expected, a gradual decrease in the proton resistance occurs with increasing ionomer content $[15,21]$. The absolute values for the proton resistance also agree well with the data published by Makharia et al [15]. By plotting proton resistance versus the volume fraction of the ionomer $(\varepsilon)$ in the electrode and fitting the experimental points with the power function of $\varepsilon$ (Figure $9 \mathrm{~b}$ ), bulk conductivity of the ionomer can be estimated. For our catalytic layers, which were 7-8 $\mu \mathrm{m}$ thick and had volume fraction of the ionomer between ca. 0.135 and 0.18 (which represents a relatively narrow region of $\varepsilon$ thereby limiting the accuracy of the fit), we estimate the conductivity of the ionomer to be ca. $85-95 \mathrm{mS} \mathrm{cm}^{-1}$, which is in a good agreement with producer specifications (Specifications of the FuMION and FuMAPEM materials can be found under: http:/ / www. fumatech.de).

It is also interesting to observe that proton resistance of the electrodes made with two different carbon supports is virtually the same. This demonstrates that, firstly, the ionomer distribution over the $\mathrm{Pt} / \mathrm{C}$ catalyst particle as well as in the catalytic layer is not influenced much by the presence of small mesopores with a diameter $\leq \mathrm{ca}$. $10 \mathrm{~nm}$ in the Sibunit-based catalyst. This indirectly indicates that small mesopores are not accessible for the ionomer particles. Secondly, interaction of the ionomer with the surface of Vulcan XC 72 and Sibunit 


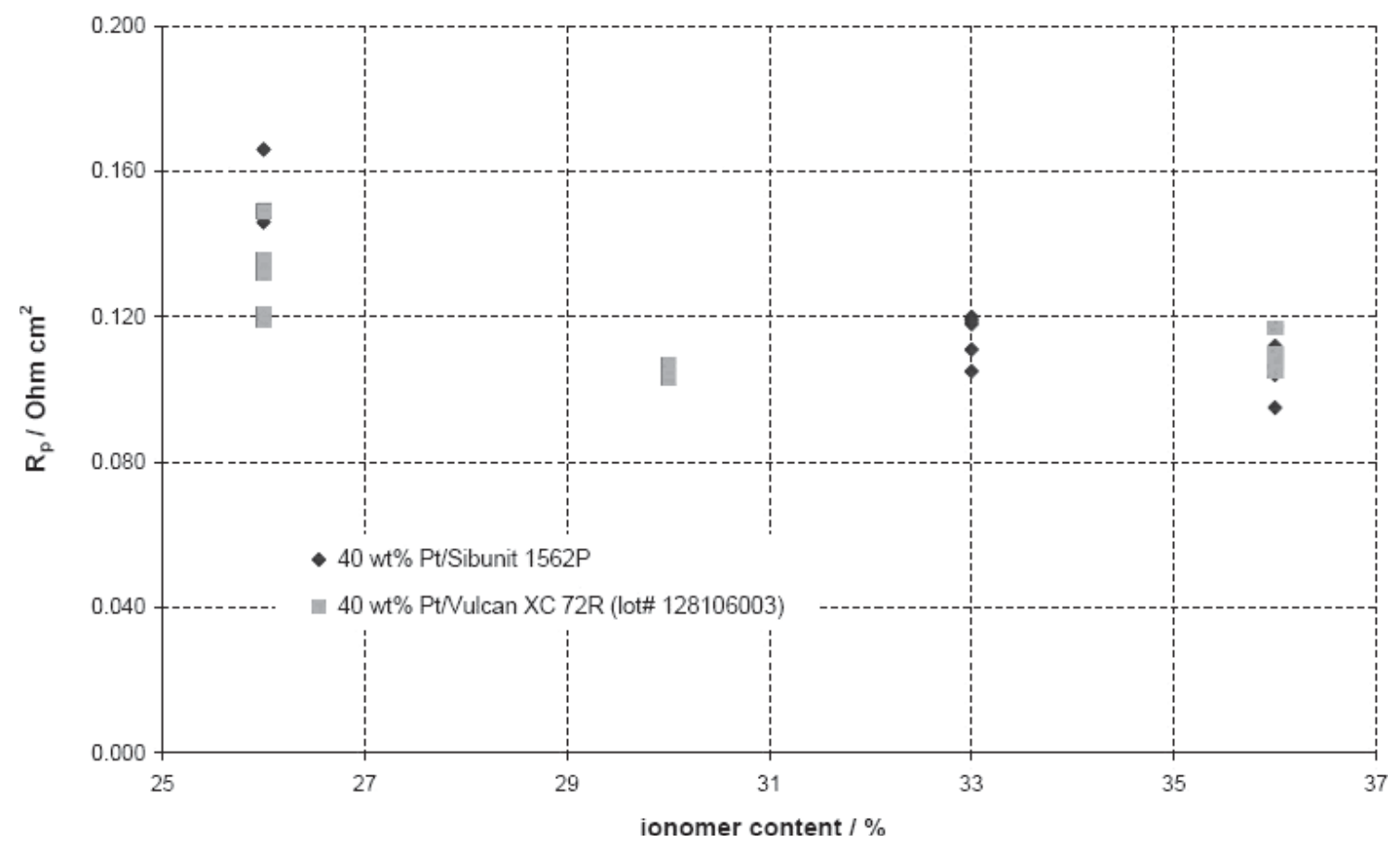

(a)

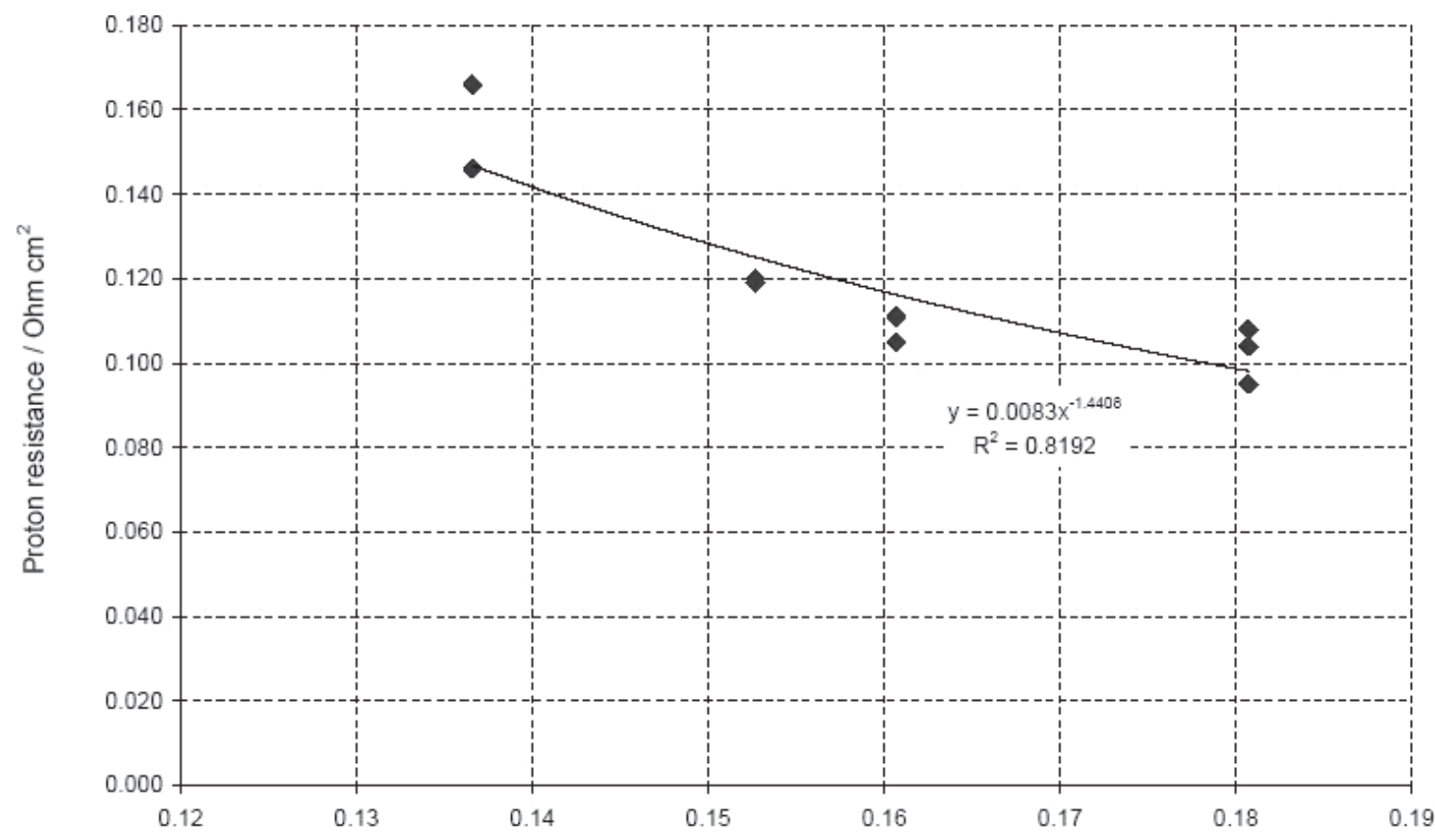

Ionomer volume fraction

(b)

Fig. 9 (a) Proton resistance of the cathode catalytic layer as a function of its ionomer content, (b) proton resistance of the cathode catalytic layer as a function of the volume fraction of the ionomer.

$1562 \mathrm{P}$ is likely to be very similar. To a certain extent, this could be expected, taking into account the similar surface microstructure of these two supports. Based on data on ${ }^{129} \mathrm{Xe}$ NMR spectroscopy of adsorbed $\mathrm{Xe}$ [30] and on the regularities of $\mathrm{H}_{2} \mathrm{PdCl}_{4}$ adsorption [31-33], obtained by Simonov et al, it is evident that fractional contribution of fragments of basal and edge planes of graphitic crystallites to the carbon surface is nearly the same among Sibunit carbons and furnace blacks as Vulcan XC 72. 
Another important parameter of the catalytic layer is its ability to transport oxygen to the reaction sites and remove the product water. In order to evaluate these properties of a catalytic layer, its oxygen gain, i.e. a drop of the cell voltage when cathode is supplied with air instead of oxygen, as a function of the current density is often measured. The absolute value of oxygen gain includes a kinetic term which accounts for the lower partial pressure of oxygen in air, a term that depends on the type of the GDL used in the MEA and a term that depends on the following characteristics of the catalytic layer: proton conductivity, porous structure and hydrophobic/hydrophilic properties. Taking into account that the same type of the GDL material was used for the fabrication of both sets of MEAs studied and that proton resistances of the catalytic layers based on Sibunit 1562P- and Vulcan XC 72-supported catalysts were virtually equal, it is justified to correlate the oxygen gain observed for the two sets of MEAs with the porous structure of the catalytic layers and its ability to remove the product water. Figure 10a shows the oxygen gain as a function of the current density for the MEAs with 40 wt.-\% Pt/Sibunit $1562 \mathrm{P}$ and 40 wt.-\% Pt/Vulcan XC 72 (Hispec 4000, lot no. 128106003) - based cathodes. It can be seen that the curves are virtually identical, indicating very similar gas and water transport properties of the electrodes based on the two catalysts. This is not an entirely unexpected result, as the porous structures of the two carbon supports Sibunit 1562P and Vulcan XC 72 - differ mainly in the region of small mesopores with the diameter $\leq \mathrm{ca} .10 \mathrm{~nm}$, which do not contribute much to the gas transport [34]. The large mesoand macropores, which seem to determine the gas mass transport properties of the electrode, have a twice lower volume in Sibunit 1562P compared to Vulcan XC 72. Nevertheless, the transport properties of the two catalysts studied are very similar. The 'lack' of the transport pores in the Sibunit-based catalyst itself must have been compensated by the formation of a more open structure of the catalytic layer.

The dependence of the oxygen gain measured at $1 \mathrm{~A} \mathrm{~cm}^{-2}$ on the ionomer content of the catalytic layer is shown in Figure 10b. Oxygen gain varies only slightly with the increasing ionomer content in the catalytic layers, reaching a not-verypronounced minimum at $33 \mathrm{wt} . \mathrm{\%}$ of the ionomer content, where the proton resistance of the catalytic layer has almost reached its minimum and the gas and water transport are not yet hindered by the excessive ionomer in the pores. A virtual independence of the oxygen gain on the ionomer content observed in this work might be related to the fact that a relatively narrow range of ionomer contents is studied. It is interesting to mention that despite the fact that $40 \mathrm{wt} .-\% \mathrm{Pt} /$ Sibunit $1562 \mathrm{P}$ has a bigger amount of oxygen-containing groups on its surface compared to Hispec 4000, it would presumably make this material more hydrophilic and therefore more prone to flooding, this effect is not observed experimentally.

\subsubsection{Stability}

Stability of a catalyst is an important characteristic that for a given set of experimental conditions depends on the quality of the catalyst itself, i.e. how narrow is its metal particle distribution, as well as on the surface microstructure of the carbon support material [35, 36]. Figure 11 shows a comparison of the Pt surface loss during the normal operation of the MEA at $0.5 \mathrm{~A} \mathrm{~cm}^{-2}$ for the two catalysts studied. Although it looks like Sibunit-based catalyst is somewhat more stable under these conditions than Hispec 4000, the difference between these two materials is comparable to the experimental error making the two sets of data equal from the statistical point of view. Potential hold experiments in a liquid electrolyte showed that Sibunit-type carbons are indeed somewhat more stable than Vulcan XC 72 [37]. Further well-defined experiments aiming at the evaluation of the stability of Sibunit itself as well as Sibunit-supported Pt catalysts are being presently performed by us.

\section{Conclusion}

Preparation, characterisation and evaluation of a novel cathode catalyst for $\mathrm{H}_{2} / \mathrm{O}_{2}$ PEMFC - 40 wt.-\% Pt/Sibunit $1562 \mathrm{P}$ carbon - is presented.

Use of the catalyst preparation method based on redoxassisted hydrolysis of $\mathrm{Pt}(\mathrm{IV})$ chloride complexes in the presence of a weak reducing agent for the catalyst preparation resulted in the successful preparation of a homogeneous 40 wt.- $\%$ Pt/Sibunit 1562P material with the average Pt particle size of $3.3 \mathrm{~nm}$ as confirmed by HRTEM, XRD and CO chemisorption.

The performance of the cathodes based on the latter material was compared to that of a widely used commercially available reference material - $40 \mathrm{wt}$.- \% Pt/Vulcan XC 72R Hispec 4000 (Johnson Matthey, UK). It has been found that the mass activity of the $40 \mathrm{wt} .-\% \mathrm{Pt} /$ Sibunit $1562 \mathrm{P}$ catalyst exceeds that of a commercial benchmark by a factor of 2 due to a better dispersion of the Pt metal realised in the Sibunit supported catalyst (Pt surface area of $83 \mathrm{~m}^{2} \mathrm{~g}_{\mathrm{Pt}}{ }^{-1}$ for the Sibunit-supported catalyst versus $49.4 \mathrm{~m}^{2} \mathrm{~g}_{\mathrm{Pt}}{ }^{-1}$ for the Vulcan XC 72-based material). The utilisation of $\mathrm{Pt}$ in the novel catalyst is as high as that in the commercial Hispec 4000 benchmark material, varying from 60 to $80 \%$ depending on the ionomer content in the catalytic layer.

Mass transport properties of the two catalysts studied are virtually equal: for both catalysts, proton resistance of the cathode catalytic layer varied between ca. 0.14 and $0.10 \mathrm{Ohm} \mathrm{cm}^{-2}$, depending on the volume fraction of the ionomer, and the oxygen gain at $1 \mathrm{~A} \mathrm{~cm}^{-2}$ was between 180 and $250 \mathrm{mV}$, depending on the ionomer content in the catalytic layer.

With respect to stability of the novel catalyst, preliminary results indicate that during a normal operation of a fuel cell 


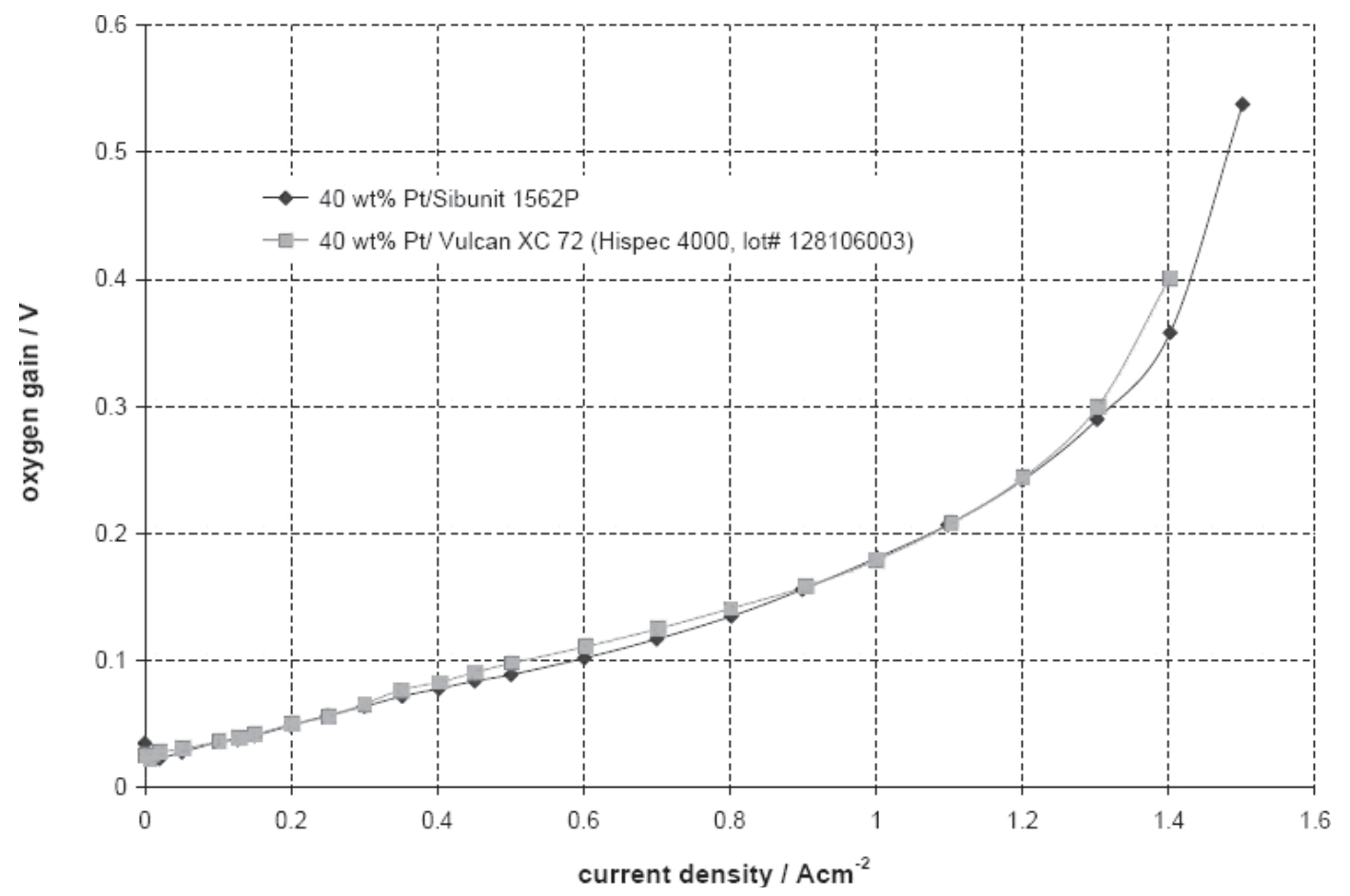

(a)

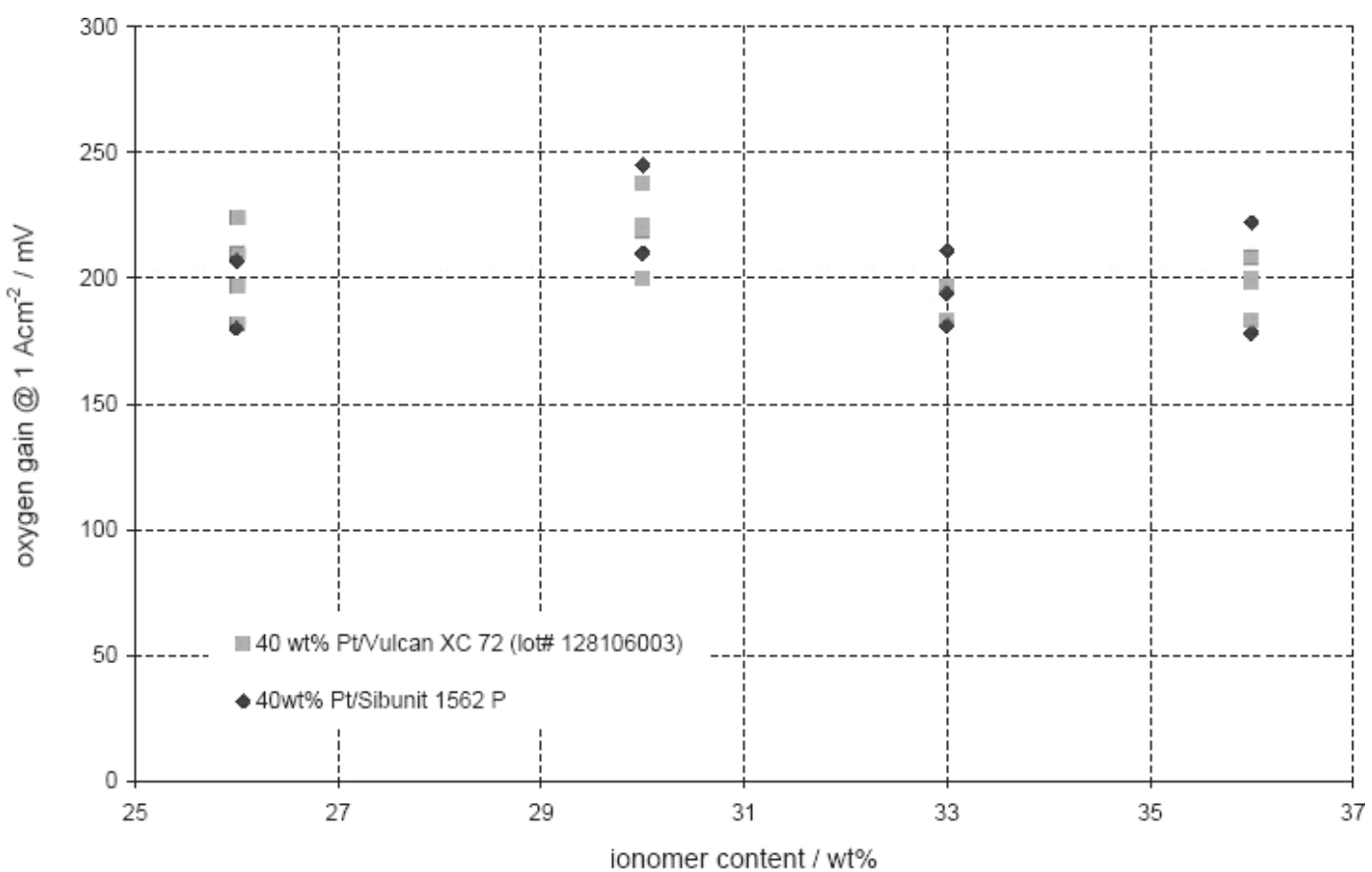

(b)

Fig. 10 (a) Oxygen gain as a function of current density for the cathodes based on 40 wt. $\%$ Pt/Sibunit 1562P and 40 wt.- $\%$ Pt/Vulcan XC $72 R$ (Hispec 4000 , lot no. 128106003) catalysts, both cathodes contained $33 \mathrm{wt} . \%$ ionomer; (b) oxygen gain at $1 \mathrm{~A} \mathrm{~cm}^{-2}$ as a function of the ionomer content in the cathode catalytic layer for 40 wt.-\% Pt/Sibunit 1562P and 40 wt.-\% Pt/Vulcan XC 72R (Hispec 4000, lot no. 128106003) materials.

at $0.5 \mathrm{~A} \mathrm{~cm}^{-2}$, the rate of the Pt surface area loss of the $40 \mathrm{wt} .-\% \mathrm{Pt} /$ Sibunit $1562 \mathrm{P}$ catalyst is comparable to that of a commercially available benchmark material.

\section{Acknowledgement}

We would like to thank Ing. Paul van den Idsert (NRG, Petten) for the TEM analysis of the Hispec 4000 material; 


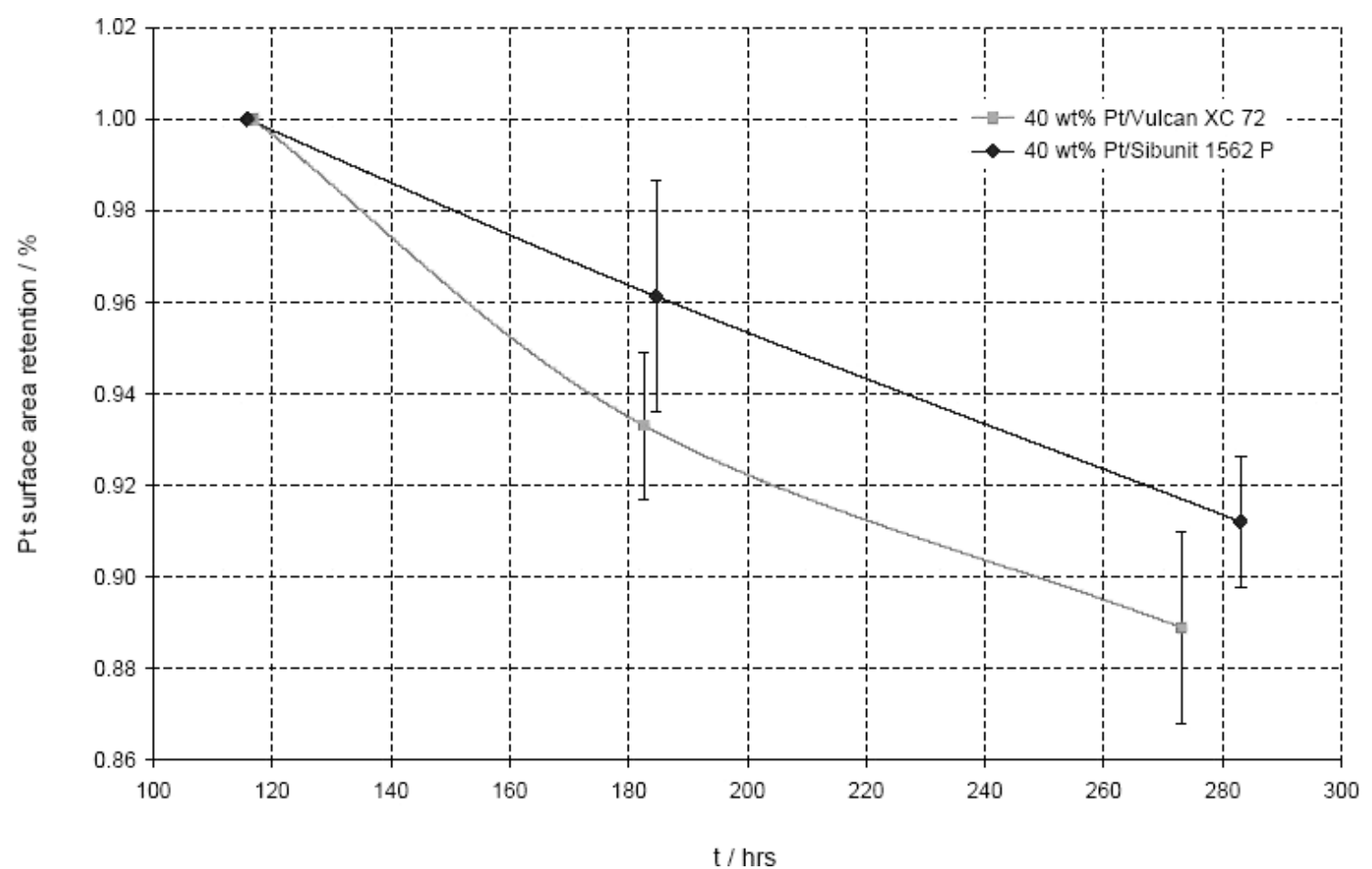

Fig. 11 Pt surface area loss of the 40 wt. $-\%$ Pt/Sibunit 1562P and 40 wt.- $\%$ Pt/Vulcan XC 72R (Hispec 4000) catalysts during a normal operation at $0.5 \mathrm{~A} \mathrm{~cm}^{-2}$.

Dr. Volker Banhardt (Freudenberg FCCT KG) for supplying the samples of H2315 C2 GDL material free of charge; Dr. Wei Zhang (FuMATech $\mathrm{GmbH}$ ) for supplying the samples of Fumion and FumaPEM and Dr. Bernd Bauer (FuMATech $\mathrm{GmbH}$ ) for useful discussions. Authors gratefully acknowledge the financial support provided by the EU-FP6 project 'IPHE-GENIE', contract no. 039016.

\section{References}

[1] K. Kinoshita, Carbon. Electrochemical and Physicochemical properties, John Willey \& Sons, New York 1988.

[2] D. Thompsett, in: Handbook of Fuel Cell: Fundamentals, Technology, and Application (Eds.: W. Vielstich, A. Lamm, H. Gasteiger), John Willey \& Sons, Chichester 2003, p. 467.

[3] T. Tada, in: Handbook of Fuel Cell: Fundamentals, Technology, and Application (Eds.: W. Vielstich, A. Lamm, H. Gasteiger), John Willey \& Sons, Chichester 2003, p. 481.

[4] M. Uchida, Y. Fukuoka, Y. Sugawara, N. Eda, A. Ohta, J. Electrochem. Soc. 1996, 143, 2245.

[5] M. Uchida, Y. Aoyama, M. Tanabe, N. Yanagihara, N. Eda, A. Ohta, J. Electrochem. Soc. 1995, 142, 2572.

[6] P. Serp, M. Corrias, P. Kalck, Appl. Catal., A:General 2003, 253, 337.

[7] J. Lee, J. Kim, T. Hyeon, Adv. Mater. 2006, 18, 2073.
[8] N. P. Lebedeva, A. S. Booij, G. J. M. Janssen, ECS Trans. 2008, 16, 2083.

[9] V. Rao, P. A. Simonov, E. R. Savinova, G. V. Plaksin, S. V. Cherepanova, G. N. Kryukova, U. Stimming, J. Power Sources 2005, 145, 178.

[10] J. Kaiser, P. A. Simonov, V. I. Zaikovskii, C. Hartnig, L. Jörissen, E. R. Savinova, J. Appl. Electrochem. 2007, 37, 1429.

[11] V. F. Surovikin, G. V. Plaxin, V. A. Semikolenov, V. A. Likholobov, I. J. Tiunova, US patent, US 4978649, 1990.

[12] Y. I. Yermakov, V. F. Surovikin, G. V. Plaksin, V. A. Semikolenov, V. A. Likholobov, A. L. Chuvilin, S. V. Bogdanov, React. Kinet. Catal. Lett. 1987, 33, 435.

[13] A. L. Vishnevskii, V. V. Molchanov, T. A. Kriger, L. M. Plyasova, International Conference On Powder Diffraction and Crystal Chemistry, St. Petersburg 20-23 June 1994.

[14] M. Eikerling, A. A. Kornyshev, J. Electroanal. Chem. 1999, 475, 107.

[15] R. Makharia, M. R. Mathias, D. R. Baker, J. Electrochem. Soc. 2005, 152, A970.

[16] K. C. Neyerlin, W. Gu, J. Jorne, H. A. Gasteiger, J. Electrochem. Soc. 2006, 153, A1955.

[17] E. Antolini, L. Giorgi, A. Pozio, E. Passalacqua, J. Power Sources 1999, 77, 136.

[18] G. Sasikumar, J. W. Ihm, H. Ryu, J. Power Sources 2004, 132,11

[19] J. Xie, K. L. More, T. A. Zawodzinski, W. H. Smith, J. Electrochem. Soc. 2004, 151, A1841. 
[20] As explained in [16] mass transport limitations occurring already in the kinetic region of a MEA not specifically designed for the determination of the kinetic parameters of the catalyst would obscure the data for the kinetic analysis. In our case at extreme ionomer contents (26 and 36 wt.-\%) this might well be the case, causing underestimation of the specific activity of both catalysts at these points.

[21] G. J. M. Janssen, E. F. Sitters, J. Power Sources 2007, 171, 8.

[22] K. A. Mauritz, R. B. Moore, Chem. Rev. 2004, 104, 4535.

[23] B. Bauer, Personal Communication between N. Lebedeva and B. Bauer, Managing Director FuMA-Tech GmbH, Nov. 20th, 2008.

[24] K. Malek, M. Eikerling, Q. Wang, T. Navessin, Z. Liu, J. Phys. Chem. C 2007, 111, 13627.

[25] J. M. Song, S. Suzuki, H. Uchida, M. Watanabe, Langmuir 2006, 22, 6422.

[26] M. K. Debe, in: Handbook of Fuel Cell: Fundamentals, Technology, and Application (Eds.: W. Vielstich, A. Lamm, H. Gasteiger), John Willey \& Sons, Chichester 2003, p. 576.

[27] Q. Wang, M. Eikerling, D. Song, Z. Liu, J. Electroanal. Chem. 2004, 573, 61.

[28] J. McBreen, J. Electrochem. Soc. 1985, 132, 1112.

[29] U. A. Paulus, Z. Veziridis, B. Schnyder, M. Kuhnke, G. G. Scherer, A. Wokaun, J. Electroanal. Chem. 2003, $541,77$.
[30] P. A. Simonov, S. V. Filimonova, G. N. Kryukova, E. M. Moroz, V. A. Likholobov, T. Kuretzky, H. P. Boehm, Carbon 1999, 37, 591.

[31] Y. A. Ryndin, O. S. Alekseev, P. A. Simonov, V. A. Likholobov, J. Mol. Catal. 1989, 55, 109.

[32] A. V. Romanenko, P. A. Simonov, in: Promyshlennyi Kataliz $v$ Lektsiyakh (Industrial catalysis in lectures), Vol.7 (Ed.: A. S. Noskov), Kalvis, Moscow, 2007, p. 7 (in Russian).

[33] P. A. Simonov, E. M. Moroz, A. L. Chuvilin, V. N. Kolomiichuk, A. I. Boronin, V. A. Likholobov, Stud. Surf. Sci. Catal. 1995, 91, 997.

[34] D. M. Ruthven, Principles of Adsorption and Adsorption Processes, John Willey\&Sons, New York 1984.

[35] P. A. Simonov, V. A. Likholobov, in: Catalysis and Electrocatalysis at Nanoparticle Surfaces (Eds.: E. R. Savinova, A. Wiechowski, C. G. Vayenas), Marcel Dekker, New York 2003, p. 409.

[36] R. Borup, J. Meyers, B. Pivovar, Y. S. Kim, R. Mukundan, N. Gartand, D. Myers, M. Witson, F. Garzon, D. Wood, P. Zelenay, K. More, K. Stroh, T. Zawodzinski, J. Boncetta, J. E. McGrath, M. Inaba, K. Miyatake, M. Hod, K. Ota, Z. Ogumi, S. Miyata, A. Nishikata, Z. Siroma, Y. Uchimoto, K. Yasuda, K.-I. Kimijima, N. Iwashita, Chem. Rev. 2007, 107, 3904.

[37] E. R. Savinova, Paper Presented at the 7th Spring Meeting of the International Society of Electrochemistry, Universite Louis Pasteur, Szczyrk, Poland, 22-25 March 2009. 